\title{
PENDIDIKAN BERBASIS STAKE HOLDERS TEORI DAN IMPLIKASINYA PADA MANAJEMEN PERGURUAN TINGGI
}

\author{
Nurul Lail Rosyidatul Mu'ammaroh \\ Fakultas Psikologi dan Ilmu Pendidikan Universitas Islam Raden Rahmat Malang \\ E-mail: rosyunira@gmail.com
}

\begin{abstract}
Universities are still in the process of transitioning to the global level; therefore universities require autonomy, accountability, legitimacy, and credibility. The backwardness of the education sector must be pursued by improving the education system, and higher education as an organization must be able to adapt to these changes so as not to suffer from increasingly fierce competition. One significant effort is to reform education through innovation and creativity. Consequently, the above needs and the objectives of implementing higher education, it requires that the management of higher education institutions be carried out professionally. This can be realized when the college has an excellent strategic management plan because with proper planning the organization will be able to walk towards achieving its goals and sustainability, as well as the function of the institution as a protected educational institution. The implementation of higher education based on stakeholders inevitably must have a plan for a sustainable organizational and educational activity strategy, in accordance with the conditions of the internal environment and the external environment (competition with similar universities, regulators, inflation/ economic conditions, etc.) so that universities always have excellence competitiveness, added value and differentiation to satisfy stakeholders, which in turn make the acceptance of higher education continuously exist, respected and needed by the community.
\end{abstract}

Keywords. Education Management, Stake Holders, College

Abstrak. Perguruan tinggi sampai saat ini masih dalam proses transisi kearah global, oleh karenanya perguruan tinggi memerlukan otonomi, akuntabilitas, legitimasi dan kredibilitas. Ketertinggalan bidang pendidikan harus dikejar dengan memperbaiki sistem pendidikan, dan perguruan tinggi sebagai organisasi harus dapat beradaptasi dengan perubahan ini agar tidak terpuruk menghadapi persaingan yang semakin ketat. Salah satu upaya penting adalah dengan mereformasi pendidikan melalui inovasi dan kreatifitas. Konsekuensi dari kebutuhan diatas dan tujuan penyelenggaraan perguruan tinggi, maka mengharuskan pengelolaan perguruan tinggi dijalankan secara profesional. Hal ini dapat terwujud manakala perguruan tinggi tersebut memiliki perencanaan pengelolaan strategis (Management Strategic Plan) yang baik, sebab dengan perencanaan yang baik organisasi akan dapat berjalan terarah mencapai citacitanya dan berkelanjutan, serta fungsi institusi sebagai lembaga pendidikan terlindungi. Implementasi pendidikan tinggi berbasis stakeholders mau tidak mau harus memiliki perencanaan strategi aktivitas organisasi dan pendidikan yang berkelanjutan, sesuai dengan kondisi lingkungan internal dan lingkungan eksternal (persaingan dengan perguruan tinggi sejenis, regulator, inflasi/kondisi perekonomian, dll.) agar perguruan tinggi senantiasa memiliki keunggulan daya saing, nilai tambah dan diferensiasi untuk mernuaskan stakeholders yang pada gilirannya membuat penerimaan perguruan tinggi tersebut secara berkelanjutan eksis, dihargai dan dibutuhkan masyarakat.

Kata Kunci. Manajemen Pendidikan, Stake Holders, Perguruan Tinggi. 
Copyright (C) JMPI: Jurnal Manajemen Pendidikan Islam. All Right Reserved. This is an open access article under the CC BY-NC-ND license (http://creativecommons.org/licenses/by-nc-nd/4.0/).

\section{A. PENDAHULUAN}

Pendidikan di bangsa manapun merupakan cikal bakal kemajuan dan kemakmuran suatu bangsa/Negara. Pendidikan adalah salah satu aspek perkembangan pemikiran. Arus globalisasi yang ditandai dengan dunia tanpa sekat menjadikan peningkatan ilmu pengetahuan dan teknologi dunia yang luar biasa, mengubah nilai sosial budaya dan lingkungan, dan membuat lingkungan usaha mengalami perubahan-perubahan yang sangat cepat baik internal maupun eksternal dari waktu ke waktu. Salah satu manifestasi globalisasi pendidikan tinggi adalah berkembangnya pasar pendidikan tinggi tanpa batas. Disisi lain, Sistem Pendidikan Nasional (UU No. 20 tahun 2003) menyatakan bahwa pendidikan nasional berfungsi mengambarkan kemampuan dan membuat watak serta peradaban bangsa yang bermartabat dalam rangka mencerdaskan kehidupan bangsa, bertujuan untuk berkembangnya potensi peserta didik agar menjadi manusia yang beriman dan bertaqwa kepada TuhanYang Maha Esa, berakhlak mulia, sehat, berilmu, cakap, kreatif, mandiri, dan menjadi warga negara yang demokratis serta bertanggung jawab. Tujuan penyelenggaraan perguruan tinggi (PP NO. 60 tahun 1999) adalah (1) menyiapkan peserta didik menjadi anggota masyarakat yang memiliki akademik dan atau profesional menerapkan, mengembangkan dan atau menciptakan IPTEK dan atau kesenian, (2) mengembangkan dan menyebarluaskan IPTEK dan atau kesenian serta mengupayakan penggunaannya untuk peningkatan taraf hidup masyarakat dan memperkaya kebudayaan nasional. Sedangkan Visi Pendidikan Tinggi Indonesia (HELTS 2003-2010) rnengharapkan bahwa pada tahun 2010 telah dapat diwujudkan sistim pendidikan tinggi termasuk perguruan tinggi yang sehat, sehingga mampu memberikan kontribusi pada daya saing bangsa dengan ciri :Quality (kualitas), Access $\mathcal{E}$ Equity (akses \& keadilan) dan Autonomy (otonomi).

Hal ini menuntut para pengelola, tidak terkecuali pada dunia usaila pendidikan tinggi/perguruan tinggi untuk senantiasa melakukan sejumlah penyesuaianpenyesuaian. Perguruan tinggi adalah satuan pendidikan yang menyelenggarakan pendidikan tinggi, diperlukan berubah untuk membantu memecahkan persoalan serta memberdayakan bangsa.

Sampai saat ini perguruan tinggi masih ualam proses transisi kearah global, oleh karenanya perguruan tinggi memerlukan otonomi, akuntabilitas, legitimasi dan kredibilitas. Ketertinggalan bidang pendidikan harus dikejar dengan memperbaiki sistem pendidikan, dan perguruan tinggi sebagai organisasi harus dapat beradaptasi dengan perubahan ini agar tidak terpuruk menghadapi persaingan yang semakin ketat. Salah satu upaya penting adalah dengan mereformasi pendidikan melalui inovasi dan kreatifitas. Konsekwensi dari kebutuhan diatas dan tujuan penyelenggaraan perguruan tinggi, maka mengharuskan pengelolaan perguruan tinggi dijalankan secara profesional, yaitu adanya kapabilitas dan kepastian status, adanya peningkatan partisipasi masyarakat dan auxiliary enterprise (berkembangnya aktivitas usaha perguruan tinggi tidak hanya dan penerimaan mahasiswanya). 
Hal ini dapat terwujud manakala perguruan tinggi tersebut memiliki perencanaan pengelolaan strategis (Management Strategic Plan) yang baik, sebab dengan perencanaan yang balk organisasi akan dapat berjalan terarah mencapai cita-citanya dan berkelanjutan, serta fungsi institusi sebagai lembaga pendidikan terlindungi. Fungsi institusi pendidikan yang perlu terlindungi yaitu pendidikan sebagai alat untuk mentransformasikan nilainilai kemasyarakatan dan membebaskan pendidikan dari hegemoni kekuasaan dan pendidikan harus dikembangkan pada masyarakat dan dilaksanakan dari oleh dan untuk masyarakat. Oleh karenanya, perguruan tinggi hendaknya mengoptimalkan pola pengelolaan dan layanan pendidikan dengan potensi sumber daya yang ada sesuai tuntutan lingkungan internal dan eksternal.

\section{B. PARADIGMA BARU PERGURUAN TINGGI}

Kegagalan menempatkan organisasi atau institusi pendidikan tinggi untuk memiliki kemampuan daya saing mengindikasikan kegagalan dalam mengelola perguruan tinggi. Hal ini dapat dikarenakan organisasi tersebut strategi pengembangannya kurang balk, pengelolaan mutu layanan tidak dikembangkan dalam visi dan misi yang jelas sehingga mutu layanan menj adi kurang sesuai dengan tuntutan internal-eksternal, dan lemahnya keikutsertaan atau keterlibatan setiap individu dalam pengeloiaan.

Problem besar perguruan tinggi dewasa ini (Amijaya, 1999) adalah rendahnya produktivitas, keterbatasan perluasan kesempatan masyarakat memperoleh pendidikan, keterbatasan kemampuan perguruan tinggi berkembang, distribusi yang tidak seimbang dalam bidang ilmu yang disediakan perguruan tinggi dengan kebutuhan kerja, dan kepincangan layanan atau k-ualitas di perguruan tinggi. Secara induktif pendidikan tinggi di perguruan tinggi dikatakan bermutu apabila perguruan tingginya berorientasi pada pemenuhan kebutuhan stakeholders, yaitu mampu memenuhi kebutuhan masyarakat (societal needs), kebutuhan dunia kerja (industrial needs) dan kebutuhan professional (professional needs) melalui Tri Dharma Perguruan tinggi. Sementara itu pengurangan peran pemerintah/Negara juga mengalami perubahan yang sangat signifikan baik secara konseptual dan praktikal. Pemerintah tidak lagi sebagai lembaga sentral yang menetapkan segala ketentuan dengan rinci, tetapi pemerintah hanya memberikan kerangka dasar dan mendorong setiap perguruan tinggi meningkatkan standart kualitasnya. Dengan demikian perguruan tinggi berfungsi selain untuk meningkatkan kualitas sumber daya manusia (SDM) yang menguasai saint dan teknologi, tetapi juga hams mengembangkan seluruh bidang saint, teknologi, ilmu-ilmu sosial dan humaniora melalui research $\mathcal{E}$ development.

Hal ini menjadikan paradigma baru pada pendidikan tinggi dalam manajemen perguruan tinggi. Paradigma ini membawa konsekuensi dalarn (1) pola perguruan tinggi untuk mengubah sistem pendidikannya berbasis masyarakat (stakeholders based education), (2) pemberdayaan sumber daya manusia (yaitu mahasiswa sebagai aktor utama, pendekatan pendidikan yang inovatif oleh dosen dan kinerja staff administrasi), (3) pola manajemennya, dan mengimplementasikannya. Perubahan-perubahan ini sudah tentu tidak instant, perguruan tinggi perlu perencanaan dan strategystrategy untuk mencapai atau mewujudkannya. 


\section{STRATEGI MENGELOLA PERGURUAN TINGGI VS MENGELOLA ORGANISASI BISNIS}

Aspek dan falsafah yang mendasari dan tujuan yang hendak dicapai berbeda antara organisasi bisnis dan organisasi pendidikan. Pada organisasi bisnis sangatlah jelas aktivitas organisasi didasari oleh falsafah yang terdiri dari nilai-nilai persaingan bebas antar organisasi bisnis yang sejenis dengan mendayagunakan sumber-sumber yang dimiliki, untuk mencapai tujuan mempertahankan dan mengembangkan eksistensi masing - masing dalam jangka panjang, melalui kemampuannya memperoleh keuntungan (laba) yang berkelanjutan. Sedangkan pada organisasi pendidikan, disamping aktivitas didasari oleh persaingan antar organisasi pendidikan itu sendiri, juga aktivitas didasarkan pada falsafah yang terdiri dart nital-nilal pengabdian dan kemanusiaan untuk mencerdasan kehidupan bangsa. Lebih fokus dapat dinyatakan, perbedaan kedua organisasi ini terletak pada tata kelolaannya.

Pada organisasi bisnis manajemen memiliki otonomi dalam menjalankan manajemennya yaitu dengan bebas mengembangkan organisasi dan memilih pengimplementasian manajemen stratejiknya. Sedangkan pada organisasi pendidikan, organisasi diatur dengan manajemen umum oleh pemerintah pusat atau pemerintah daerah yang secara terencana dan sistimatis telah menetapkan berbagai pengaturan yang mengikat perguruan tinggi dalam memilih dan mengimplementasikan manajemen strateginya.

Pendidikan tinggi seharusnya menjunjung tinggi kebebasan akademik. Berangkat dari pemikiran, bahwa pendidikan tinggi adalah tempat untuk belajar, maka setiap individu bebas mempelajari apa yang ingin diketahainya. Sementara tidak semua yang ingin dipelajari tersedia dan tersampaikan dalam satuan pendidikan. Dengan demikian, tidak ada alasan untuk menghalangi informasi pengetahuan dan semua aktivitas yang dilakukan demi kemajuan ilmu pengetahuan serta penerapannya di masayarakat

Dalam upaya merekonstruksi pendidikan tinggi ini, maka keberadaan mabda (ideology) merupakan salah satu aspek penting yang menentukan. Mabda merupakan aqidah aqliyah (difahami melalui proses berfikir) yang melahirkan segenap peraturan untuk memecahkan problematika kehidupan termasuk masalah pendidikan. Pada mabda Islam manusia diarahkan untuk membangun sebuah peradaban yang mulia melalui tegaknya institusi Negara yang menjamin terpeliharanya aqidah dan syariah dalam kehidupan. Dalam pendekatan sistemik, untuk mencapai tujuan pendidikan tinggi yang terjaga mabdanya dengan memperhatikan kondisi lingkungan internal dan eksternal dan perubahan tuntutan pemerintah masyarakat dan dunia kerja (stakeholders), maka diperlukan perencanaan strategi dalam pengelolaan perguruan tinggi (management strategic on higher education). Ushlub (strategi) yang dapat digunakan diantaranya yaitu defensive strategy dan recovery strategy. Defensive strategy pada intinya bertujuan untuk mempertahankan prestasi yang telah dicapai di masa silam dan sekaligus berusaha sedapat mungkin meningkatkan segala sesuatu yang baik, dan Recovery strategy bertujuan untuk memulihkan kembali pendidikan nasional dari berbagai krisis yang masih akan bertahan dalam beberapa tahun kedepan.

\section{MANAJEMEN STRATEGI SEBAGAI PARADIGMA BARU PENDIDIKAN TINGGI}

Manajemen yang berasal dari kata 'to manage' yang berarti suatu untuk merencanakan, mengorganisasikan, mengarahkan dan mengendalikan organisasi dan 
semua perangkatnya untuk mencapai tujuan organisasi. Dalam konteks organisasi yang bersifat non profit manajemen didefinisikan sebagai ilmu dan seni yang berupaya secara sistematis untuk memahami mengapa dan bagaimana manusia bekerja bersama untuk mencapai tujuan dan membuat system kerja yang bermanfaat bagi kemanusiaan. Management (Lewis, 2002) is the discipline of planning, organizing, and managing resources (as money, people, materials, energy, space, provisions, communication, motivation, etc.) to bring about the successful completion of specific project goals and objectives. Menurut Comninos (2002) Management is the application of $f$ knowledge, skills, tools and techniques to project activities to meet project requirements. Management means, in the last analysis, the substitution of thought for brown and muscle, of knowledge for folklore and superstition, and of co-operation for force. Sedangkan Management menurut Drucker (Byrne, 2005) is the group of individuals who make decisions about how a business is run. The basic task of a management is twofold: marketing and innovation. As a discipline, management comprises of the interlocking functions of formulating corporate policy and organLing, planning, controlling and directing the firms resources to achieve the policy's objectives. Dengan demikian secara tradisional manajemen dapat dikatakan secara umum sebagai aktivitasaktivitas yang melibatkan empat fungsi yaitu perencanaan, pengorganisasian sumber-sumber, peranan dan pengendalian sebagai pengkoordinasian. Sedangkan secara modern, terdapat empat kedudukan manajemen yaitu memutuskan, merencanakan, mengatur dan mengukur.

Strategi (ushlub) adalah cara untuk mencapai tujuan dengan daya dan sarana yang dapat dihimpun, cara-cara yang sifatnya mendasar dan fundamental yang akan dipergunakan oleh suatu organisasi untuk mencapai tujuan dan berbagai sasarannya. Menurut David (2003) strategy is ways for achieve to objectives long term. Hakikat suatu strategi adalah cara berpikir manusia secara sistematik, kreatif dan dinamis yang selaras dengan keadaan.

Dengan demikian strategi memiliki sifat-sifat: (1) unifield, menyatukan seluruh bagian-bagian dalam organisasi, (2) Comprehensive, mencakup seluruh aspek dalarn organisasi, (3) Integral, seluruh strategi akan sesuai dengan seluruh tingkatan (corporate business and functional). Sehingga Sesuatu dapat disebut strategi apabila, (1) Orientasi ke masa depan/dimensi waktu, yaitu suatu pola keputusan yang konsisten, menyatu dan integral, (2) Alokasi sumber sumber daya, yaitu menentukan dan menampilkan tujuan organisasi dalam artian sasaran jangka panjang, program bertindak dan prioritas pada alokasi sumber daya, (3) Komitmen manajemen puncak, yaitu menyeleksi bidang yang akan digeluti organisasi, (4) Pengaruh jangkq panjang, yaitu mencoba mendapatkan keuntungan yang mampu bertahan lama, dengan memberikan respon yang tepat terhadap adanya peluang dan ancaman dari lingkungan eksternal organisasi dan kekuatan serta kelemahan nya, dan (5) Berhubungan dengan unit-unit kegiatan yang kompleks, yaitu melibatkan semua tingkat hirarki organisasi, sehingga untuk memutuskan strategi yang digunakan organisasi perlu melakukan formulasi strategi yang akan diimplementasikan.

Management strategic merupakan puncak dari ilmu dan aplikasi manajemen. Disebut strategic karena hanya pimpinan-pimpinan puncak yang mampu mengendalikannya, kendati dibutuhkan support semua organisasi untuk menjalankannya. Pada management strategic ditentukan kemana arah institusi akan dibawa. Management strategic menghimpun semua kekuatan untuk memperoleh keunggulan daya saing. Lamb (1984) menyatakan bahwa Strategic Management is an going 
process that assesses the business and the industries in which the company is involved, assesses its competitors and set goals and strategies to meet all existing and potential competitors, the reasseses each strategy annually or quarterly to determine how it has been implemented and whether it has succeeded or needs replacement by a new strategy to meet change circumstances, new technology, new competitors, a new economic environment, or a new social, financial or political environment. Sedangkan David (2003) menyatakan Management Strategic is the art and science of formulating, implementing and evaluating crossfunctional decisions that will enable on organization to achieve its objectives. Berpijak dari pendapat-pendapat diatas, maka dapat dikatakan tujuan manajemen strategis adalah memanfaatkan dan menciptakan peluang-peluang baru dan berbeda di masa mendatang. Hal ini sejalan dengan apa yang dimaksud dalam istilah perencanaan strategis yang popular di pertengahan tahun 1960-an yaitu mencoba mengoptimalkan kecenderungan-kecenderungan saat ini untuk masa depan. Istilah perencanaan strategis iebih sering digunakan dikalangan bisnis, sedangkan istilah manajemen strategis digunakan di banyak akademi dan universitas.

Proses manajemen strategis terdiri dari 3 tahap (David, 2003) yaitu formulation strategy, implementation strategy and evaluation strategy. Langkah awal memformulasi/merumuskan strategi adalah merubah tantangan menjadi suatu keunggulan bersaing, yaitu setelah mengembangkan Visi dan Misi organisasi selanjutnya melakukan proses evaluasi diri (SWOT Analysis) terhadap lembaga, sumber daya manusia, dan semua sumber daya yang ada secara jelas dan akurat untuk menetapkan tujuan jangka panjang organisasi, membuat sejumlah strategy alternative dan memilih strategy tertentu untuk eksistensi organisasi secara berkelanjutan. Input organisasi bidang pendidikan yang dianalisis meliputi M9P yang terdiri dari Man, Money, Material, Machine, Method, Media, Market, Minute, Memory dan Place.

Kecenderungan organisasi pendidikan tinggi atau perguruan tinggi terhadap kompetisi bisnis di bidang pendidikan dalam konteks globalisasi, dimana pendidikan tinggi memainkan peran sentral dalam membangun masyarakat berpengetahuan, yang tercermin pada munculnya lapisan kelas menengah terdidik dan kaum professional yang menjadi kekuatan penentu kemajuan, maka menjadikan manajemen perguruan tinggi suka tidak suka mau tidak mau harus berorientasi market driven untuk dapat memenuhi kebutuhan stakeholders. Sehingga pengelola perguruan tinggi harus berinovasi dan mengkreasi Marketing mix, yang dalam bidang jasa pendidikan terdiri dari 9P yaitu Price, Prospect, Product, Profit, Priority, Place, People, Profile and Promotion. Akibatnya, dalam pengelolaan perguruan tinggi (manajemen perguruan tinggi) perlu mempertimbangkan competition, competitive advantage, added value dan differentiation untuk dapat membuat customer satisfaction (impressive experienced and satisfied services).

Dengan demikian alternative strategi untuk keunggulan bersairig dapat dibangun melalui jaminan kualitas (Qualitv Assurance), pelayan yang mengesankan (Best Services), kelulusan yang cepat (Fast Delivery), tempat yang indah, bersih, menyenangkan (Clean lines), dan bebas narkoba, free sex, dll (Health $\mathcal{E}$ Safety), atau dapat kita istilahkan untuk memudahkan menginggat dengan sebutan ACSECCUL (Academic Services Corporate Cultural). 


\section{E. IMPLEMENTASI}

Manajemen strategi pada dasarnya merupakan suatu paradigma baru dalam mengelola bidang pendidikan. Sebagai paradigma baru maka mengimplementasikan strategi manajemen pada organisasi pendidikan tidaklah dilakukan sebagaimana aktivitas pengambilalihan seluruh aktivitas organisasi sebagaimana pada organisasi bisnis. Dengan mengimplementasikan manajemen stratejik pada pengelolaan perguruan tinggi, maka akan tercipta atribut kompetisi, output, outcome maupun impact yang link and match dengan pasar kerja. Implementasi manajemen strategi direalisasikan dalam Renstra (Rencana Strategis) dan Renop (Rencana Operasional) yang berfungsi sebagai pengendali dalam mempergunakan sernua sumber daya yang dimiliki secara terintegrasi dalam pelaksanaan fungsi-fungsi manajemen, agar berlangsung sebagai proses yang efektif dan efisien. Salah satu faktor keberhasilan suatu organisasi (lembaga) pendidikan adalah dukungan tim kerja pelayanan akademik yang adaptif, fleksibel, cepat tanggap, solid clan pantang menyerah. Disamping itu para pendidik selain diberdayakan oleh para peagelola, juga harus dibuat bangga dengan cara pemenuhan self esteem dan self actual Lationnva.

Dalam konteks paradigma baru perguruan tinggi pada dasarnya tujuan jangka penjang yang dijabarkan dalam aktivitas program strategi dapat bertumpu pada tiga (3) hat yaitu (1) kemandirian dan kewenangan pengelolaan (manajemen dan kurikulum) yang lebih luas (otonorni), (2) akuntabilitas kepada stakeholders (fihak yang sangat berkepentingan dengan perguruan tinggi) dalam hal pernanfaatan sumber-sumber keuangan, pengembangan keilmuan, program-program yang diselenggarakan, dan (3) jaminan kualitas yang lebih besar. Ketiga hal ini saling berkaitan satu sama lain dan interdependensi diantaranya, sehingga ketiganya harus diimplementasikan secara simultan. Persoalannya, suatu perguruan tinggi keberadaannya dipengaruhi oleh faktor internal dan eksternal, yang tidak jarang belum banyak memungkinkan terciptanya iklim yang betul-betul kondusif bagi implementasi strategi manajemennya. Disisi lain adanya tuntutan stakeholders pendidikan sangat mungkin akan membuat pendidikan terlepas dari konsep konsepnya yang idealis, karena untuk memenuhi kebutuhan dunia kerja seringkali memanfaatkan pendidikan sebagai pabrik, sehingga pendidikan dapat menjadi lahan bisnis baru dan, mirisnya kondisi semacam ini membuat para pengelola pendidikanpun larut. Ironisnya, opini yang terbentuk pada masyarakat bahwa pendidikan adalah jalur utama memperoleh kesuksesan/keberhasilan. Hal inilah yang kemudian rnenjadi peluang bagi pengelola pendidikan tinggi.

Paradigma yang ada, bahwa perguruan tinggi selain sebagai lembaga pendidikan tinggi juga sebagai lembaga bisnis jasa di bidang pendidikan, memerlukan waktu yang sangat panjang untuk dirubah. Perlu langkah panjang untuk merubah kalangan intelektual akademisi. Dengan demikian sangat penting memperhatikan bagaimana sikap manajemen suatu organisasi perguruan tinggi menyikapi agar perguruan tinggi yang seharusnya merupakan organisasi nirlaba tidak larut dalam kegiatan bisnis semata, namun tetap mempertahankan nilai-nilai dari suatu pendidikan. Bukankah, tujuan hakiki per.didikan adalah untuk meningkatkan kualitas hidup umat manusia, mengambarkan pengetahuan yang secara praksis berguna bagi masyarakat dan bukan hanya golongan tertentu.

Dengan demikian batasan nilai pendidikan telah bergeser dari pendidikan 
sebagai nilai pengetahuan dan keahlian intelektual inenjadi pengembangan kemampuan individu yang mana berimplikasi pada perubahan strategis institusi pendidikan tinggi, yaitu menjadi pengembangan keahlian kemampuan dan kualitas kerja, sebagaimana pendapat Stephenson (1998) which focuses on the limited value of education as knowledge and intellectual skill is rapidly becoming a thing of the past. The new focus is on developing the individuals capability. Thus these recent changes $A$ the context of improving skills, life long learning and making the transition from welfare to work. These change all relate to improving capability and quality learning and the authors debate the issues within the setting of institutional strategies work-based learning, skills, development and assessment.

\section{F. KESIMPULAN}

Berdasarkan uraian tersebut diatas, maka dapat dilakukan kesimpulan tentang pendidikan tinggi berbasis stakeholders, implementasi pendidikan tinggi berbasis stakeholders, dan manfaat management strategic dalam pola organisasi perguruan tinggi, yaitu :

1. Pendidikan tinggi yang diselenggarakan perguruan tinggi sesuai Peraturan Pemerintah No. 60/1999 membawa konsekwensi pada paradigma baru pola perguruan tinggi, untuk mementingkan berbagai fihak yang berkepentingan dengan perguruan tinggi (stakeholders) seperti masyarakat, pemerintah dan dunia kerja, dll.

2. Implementasi pendidikan tinggi berbasis stakeholders mau tidak mau harus memiliki perencanaan strategi aktivitas organisasi dan pendidikan yang berkelanjutan, sesuai dengan kondisi lingkungan internal dan lingkungan eksternal (persaingan dengan perguruan tinggi sejenis, regulator, inflasi/kondisi perekonomian, dll.) agar perguruan tinggi senantiasa memiliki keunggulan daya saing, nilai tambah dan diferensiasi untuk mernuaskan stakeholders yang pada gilirannya membuat pen.-rimaan perguruan tinggi tersebut secara berkelanjutan eksis, dihargai dan dibutuhkan masyarakat.

3. Manfaat memiliki strategic management plan:

a. Menjadikan aktivitas perguruan tinggi terarah dan berkelanjutan dalam mencapai cita-citanya karena akan lebih mudah dalam menyepakati perubahan dan pengembangan strategi yang akan dilakukan.

b. Fungsi control menjadi lebih efektif dan efisien karena output, outcome dan impact dapat terukur.

c. Setiap individu dan komponen organisasi yang ada di perguruan tinggi serta stakeholder dapat proaktif dan terlibat dalam mewujudkan keunggulan perguruan tinggi.

d. Mengimplementasikan strategic management untuk mencapai tujuan harus memiliki komitmen kuat, terbangun budaya yang berorientasi pada kebutuhan fihak-fihak yang berkepentingan.

\section{REFERENSI}

Amijaya, D.A. Tisna. (1976). Kerangka Pengembangan Pendidikar, Tinggi Jangka Panjang. Jakarta: Dirjen-Dikti.

Byrne, John A. (2005). The Man Who Invented Management. Business Week, November 28. 
Comninos D \& Frigenti E., (2002), The Practice Of Project Management -A Guide To The Business Focused Approach. London: Kogan Page.

David, Fred R. (2003). Strategic Management, Ninth Edition. New Jersey: Pearson Education.

Drucker, F Peter. (1994), Managing The Non Profit Organization. London: Harper Business.

Stephenson, John \& Mantz Yorke. (1998). Capability and Quality in Higher Education. London: Kogan Page Limited.

Lamb, Robert, Boyden. (1984). Competitive Strategic Management, New York: Englewood Cliffs, Prentice Hall.

Lewis, James. (2002). Fundamental Of Project Management, 2nd ed. American Management Association.

Michael Shattock. (2003). Managing Succesful Universities The Society For Research Into Higher Education and Open. University Pres.

Peraturan Pemerintah No. 60 Tahun 1999, Pendidikan Tinggi.

Undang-Undang, 2003, Sistem Pendidikan Nasional. 